\title{
Teaching Chemistry with Computers
}

\author{
Hua-Jun Fan, Joshua Heads, Daniel Tran, and Nnenna Elechi
}

\begin{abstract}
With a new generation of undergraduate students who are savvy with technologies and computers, coupled with the advancements in computer hardware and software development, the learning curve of computational chemistry is diminishing. We demonstrate various modules that can be used not only to illustrate the difficult concepts in chemistry education, but also to provide the hands-on experience that allow students to generate their own data and conclusions.
\end{abstract}

Index Terms-Computational chemistry, molecular modeling, undergraduate chemistry curriculum, American chemical society.

\section{INTRODUCTION}

The new generation of undergraduate students is nothing like the type of students we used to teach [1]. This new generation wants to learn things differently and quickly, and tends to have less patient to read books, though we believe that's the only way to learn the new information. To make things worse, some of these kids will never open their books before the exams, sometimes not even before the end of semester. They would search answers and concepts on Google, regardless of the accuracy and correctness of the answer. What drives some of us crazy is when some of these students would simply copy and paste online answers and claim their credit, which we call plagiarism. Chemistry is no different than any other science subjects that has encountered this very same problem.

According to a survey conducted in 1995 [2], many students describe chemistry as one of the toughest and most boring science courses they must pass, despite the fact that chemistry, a science central to technology and engineering fields in many ways, is an easy subject to apply to real life [3] The examples and applications of chemistry are abundant and unavoidable in everyday life. For example, an understanding of fundamental chemistry concepts are required to solve the oncoming energy crisis, to develop environmentally friendly methods of production and waste management, to detect biological weapons in real time, to develop better pharmaceutical drugs, to solve environmental problems, and to design newer functional nano-materials. Therefore, chemistry along with other science courses such as physics and math usually are weaved into the university core courses that almost all incoming freshmen will have to take and pass. Depending on the major and classifications, most campuses will have a chemistry course for students majoring in

Manuscript received January 15, 2014; revised March 25, 2014. This work was supported in part by the US Department of Energy - National Nuclear Security Administration (NNSA) (Award No. DE-NA0001861) and the National Science Foundation Division of Materials Research (Award No. DMR-1309510).

H. J. Fan is with the Prairie View A\&M University, Prairie View, TX 77446 USA (e-mail: HJFAN@pvamu.edu). non-science related subjects such as nursing, technology or engineering [4] and there are separate courses set up just for the chemistry, biology, and other science majors. Because the needs and the purposes of these courses are different at various campuses, there is no universal curriculum for these courses. However, all of these chemistry courses require a significant amount of foundational knowledge of electronic structures, electron configurations. After they've learned these basic fundamentals, we then demand the student to apply and correlate between the structure and property, and finally predict the properties of new materials. The job market demands our students to at least have some type of exposure. For example, the new (revised) undergraduate curricular guidelines from American Chemical Society Committee on Professional Training (ACS-CPT) suggest the foundation-level chemistry curriculum should be reorganized into three sequences: structure, reactivity, and quantization. It is believed that the new reorganization would allow students to more quickly appreciate the breadth of the field than the traditional domains.

Ever since the National Science Foundation (NSF) reformed the Chemistry curriculum with the Chemical Bond Approach (CBA) and Chemical Education Material Study (CHEM Study) in the late 1950s, and students were learning chemistry through hands-on laboratory procedures that required problem solving, and a stronger technical training in chemical principles across the board [5]. With the dilemmas and the new challenge brought upon us by this new generation of learners, they have also brought new opportunities. For example, most of them now have tons of electronic gadgets at their disposal and most of time they are online for social or entertainment purposes. There have been some researchers and educators who embrace electronic teaching such as distance learning, podcast, mini-video streaming, along with clickers, traditional power points, and transparencies. In this paper we will explore computational chemistry in undergraduate education. In particular the molecular modeling tools that are used to 1) help students understand difficult concepts such as electron configuration and structural modification, in general chemistry setting, and 2) as a research tool for advanced chemistry courses or scientific research.

\section{APPROACHES}

There are two different types of students who take chemistry: the science majors and non-science majors. In general, the science majors usually find it easier and would adapt to, if not already being trained on, the traditional conceptual approach of learning chemistry, which often is taught in the form of rigorous facts and principles and very much in an abstract manner. On the other hand, the non science majors are still in need of developing some types of 
scientific (aka chemical) literacy, which would then allow them to understand the principles, and engage in an interactive way to grasp the materials and possibly apply those principles to better understand the phenomenon around them from environmental effects to nanotechnology [6]. It is not surprise that the non-science majors find this traditional approach to chemical education difficult and boring, and are struggling to understand the relevance of conceptual chemistry. Most of these students will lose their interests in science, particularly in chemistry within the first year [7] because of the embedded requirement in core curriculum.

\section{Methodology}

In this study, we will use computational technology to expound upon various chemistry situations. As examples, we will first use it to describe the kinetics of substitution reactions. Then we will use it to explain to students the importance and effectiveness of sunscreen. Finally, we will describe how computational chemistry can be used not just in the methods listed above but in other aspects of chemistry.

By using this tactic, it allows students to produce the data quickly and draw their own conclusions as they learn from the textbook. The approach used here is to adopt the current graphic user interface (GUI) such as WebMO, Spartan, or GaussView in order to facilitate the steep learning curve of basis sets, functionals, methods and software. So the students can focus on learning the chemistry and concepts, rather than on the how-to's and set-up's. For the sake of time, semi-empirical methods such as PM3 and ZINDO [7] were used. The software used in this study is GaussView and Gaussian 09 [8]. The geometries of the compounds in the developed modules were optimized under B3LYP functional [9] with Pople's6-31G* basis set [10].

\section{RESULTS AND DISCUSSION}

One of the important and vital tasks as a chemistry educator is how to move away from the perception that chemistry is difficult and boring. This perception was developed during the early stage of Chemistry and physics around 1920s when more fundamental discoveries helped form the theoretical principles. These discoveries allowed chemistry to become more rigorous and analytical, which also made the field highly submerged in tradition [11]. As such, the material that needed to be covered in general chemistry exploded over the years. To make things worse, the new materials were simply augmented and added without evaluating their relationship to old principles. A review by Lloyd in 1992 pointed out that the typical general chemistry textbook changed from a small 5 inch $x 8$ inch book into a $1000+$ page, 8 inch $\times 10$ inch encyclopedia book that averaged 6 lbs [12].

Clearly there is a need to modernize how chemistry is taught to our new generation of students. There are many published efforts and research that has been invested in endeavors to assist students' learning, such as MIT's OpenCourseWare [13], Process Oriented Guided Inquiry Learning (POGIL) [14], Peer-led Team Learning (PLTL) [15] and context-led approaches (CLA) [16]. As their names suggest, all these approaches actively involve the students either on problem-based or real life scenario-based self-instruction and self-teaching. The results would have been somewhat successful if the approach was well planned and implemented [17]. While our approach in this study also adopted student-centered engagement, we employed computational chemistry and molecular modeling as a tool to facilitate the student learning.

The computer technology and software development has enabled modeling tools to be used on a par with experimental methods as a legitimate and practical means for exploring chemistry. Molecular modeling can offer major benefits as a tool for exploration such as studying a compound that is difficult to synthesize in a laboratory setting. The cost of making this compound on screen is essentially just the price of the software itself and the creator's imagination. However, one must be very cautious of such actions as the traditional wisdom says "Garbage in, garbage out." Therefore, the guidance from a more experienced user and instructor is essential in teaching the "right" chemistry. That way, students will not be taught improperly. Compared to the cost of synthesis, purification and characterization costs, modeling tools providecrucial information on geometries, 3-D rendering, volumes, contact areas, symmetries, reaction mechanisms, and energy profiles such as activation energies for kinetics and thermodynamic parameters such as enthalpy, entropy and Gibbs free energies.

Like any discipline, good science instruction should start with well drafted learning objectives and learning outcomes as one of the essential tools for the success of the course and a guide for students' learning. Literatures show that learning objectives and learning outcomes follow more than two dozen taxonomies that have been developed to define the domains of learning, development, and cognition [18]. However, most of them were all based on Bloom's classic Taxonomy developed in 1956 [19] as shown in Fig. 1. While Bloom's classic Taxonomy of Educational Objectives were defined by six hierarchical levels of cognitive processing, (knowledge, understand, apply, analyze, synthesize and create), a more modern version of Bloom's Taxonomy use a non-hierarchical definition of learning (knowledge, comprehension, application, analysis, synthesis, and evaluation).

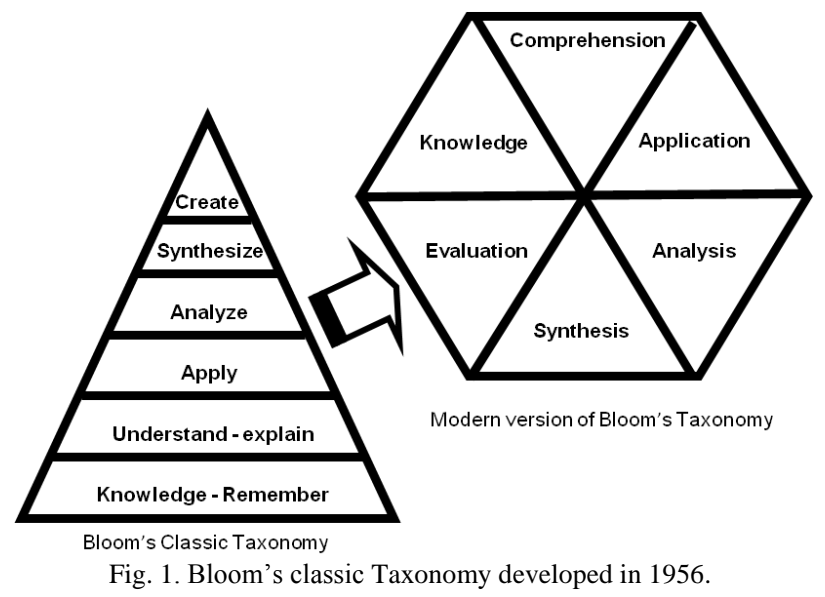

Though the words of these versions are similar, the approach to assist students' learning is quite different. The classic hierarchical approach assumes students' progress gradually from bottom up, while the non-hierarchical 
approach assumes students' learning at all levels and all aspects. These different learning skills were developed concurrently, therefore training of these skills need to be applied correspondingly. There are even other types of taxonomy such as foundational knowledge, application, integration, human dimension, caring and learning how to learn [20].Computational chemistry and modeling tools actually enable students to apply, analyze and synthesize the chemical concepts embedded in the question through the data generating, collecting, and analyzing.

Here, we will demonstrate some of the modeling modules adopted [21] and developed to illustrate how computational chemistry can effectively explain and visualize the difficult and abstract chemical concepts.

\section{A. Kinetics of Substitution Reactions}

The reaction pathway and its theories are something that is usually demonstrated via diagrams such as Fig. 2.

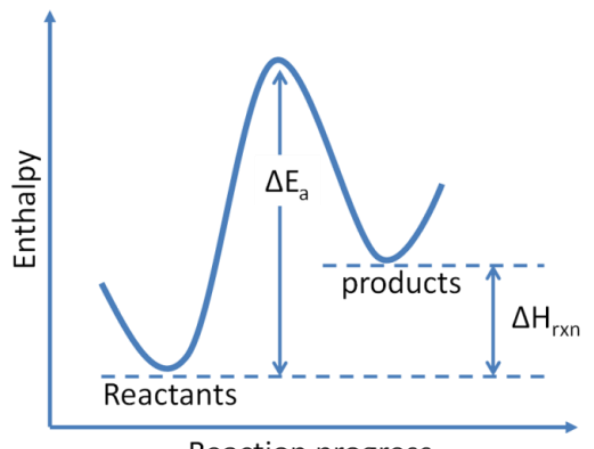

\section{Reaction progress}

Fig. 2. The energy diagram of a reaction coordinate for a simple one-step reaction.

According to the collision and transition state theory, the reactant molecules must effectively collide (geometry-wise and energy-wise) in order for the reactants to enter a transition state (TS) before they can form the products. This collision effectiveness is the key to the activation energy as depicted as $\Delta \mathrm{E}_{\mathrm{a}}$ in Fig. 2, which is the minimum energy that must be supplied by the collisions in order for a reaction to occur. The energy difference between the reactants and products determines the endothermic or exothermic energy of the reaction (See Fig. 3). Students have a hard time picturing the transition states and the collision. Therefore, a carefully designed reaction such as a one-step nucleophilic substitution reaction (SN2)of bromide with methyl chloride, could be used to illustrate the concepts. The steps implemented are:

1) Prepare the reactants $\mathrm{CH}_{3} \mathrm{Br}+\mathrm{Cl}^{-}$and the products $\mathrm{CH}_{3} \mathrm{Cl}$ $+\mathrm{Br}^{-}$

2) By fixing $\mathrm{C}-\mathrm{Br}$ bond, scan the bond distance between $\mathrm{C}-\mathrm{Cl}$ from 1.7 to $4.0 \mathrm{~A}$

3) Swap $\mathrm{Br}-\mathrm{Cl}$ position, then fix $\mathrm{C}-\mathrm{Cl}$ bond distance to the lowest energy point in above scan, scan the $\mathrm{C}-\mathrm{Br}$ bond distance from 1.7-4.0 A.

4) Deduce the possible geometry of transition state based on above steps

5) Use Scan function of Gaussian to set up automatic 2-D scan of $\mathrm{C}-\mathrm{Cl}$ and $\mathrm{C}-\mathrm{Br}$ distance and plot the geometry of transition state to be compared with the results above steps

6) Plot the relative energy of the reactants $\mathrm{CH}_{3} \mathrm{Br}+\mathrm{Cl}^{-}$the products $\mathrm{CH}_{3} \mathrm{Cl}+\mathrm{Br}^{-}$, and transition state
This process actually can be used to serve three folds of teaching: first, to provide a visualization of the geometries of reactants, products and especially the transition state motion. For example, the frequency of the transition state can yield the concerted motion of leaving group and entering group, such motion is extremely valuable to demonstrate TS.

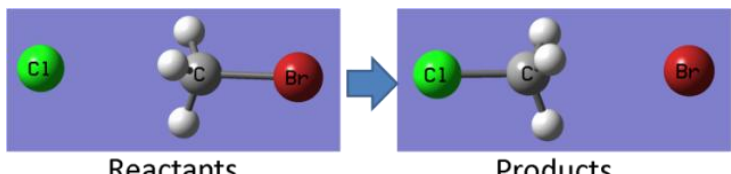

Reactants

Products

Fig. 3. Visualization of the reactants and products.

Second, providing the understand of the relationship among the Lewis dot structure, electro negativities of $\mathrm{Br}$ and $\mathrm{Cl}$, geometry and dipole moments. As shown below in Table 1 , the calculated geometric parameters are carbon-halide bond distance $(\AA)$, dipole moment (Debye), and atomic polar tensors charge and population analysis $\left(\mathrm{e}^{-}\right)$. Students can easily draw the correlation between these calculated parameters to the electro negativities and geometries of reactants and products. While the explanation provided by most textbooks is readily available, this process allows students to produce the quality data, formulate and synthesize their own conclusions.

\begin{tabular}{lllll} 
TABLE I: THE CALCUlATED PARAMETERS OF REACTANT AND PRODUCT \\
\hline \hline & Electronegativity & dipole & $\begin{array}{l}\text { C-X } \\
\text { bond }\end{array}$ & Charge on X \\
\hline $\mathrm{CH}_{3} \mathrm{Br}$ & 2.96 & 2.132 & $2.011 \AA$ & -0.232 \\
$\mathrm{CH}_{3} \mathrm{Cl}$ & 3.16 & 2.477 & $1.877 \AA$ & -0.068 \\
\hline \hline
\end{tabular}

Third, students can then search and deduce the TS geometry using steps 2 and 3, while the software generates and pinpoints the TS on the potential energy surface (PES) of reaction pathway in step 5. A PES scan along $\mathrm{C}-\mathrm{Br}$ and $\mathrm{C}-\mathrm{Cl}$ bond direction provides students the approximate location of the transition state as shown in Fig. 4. This process could allow students to see the principle and foundations behind the software in search of the transition state as well how the software identifies and evaluates the kinetics of a reaction.

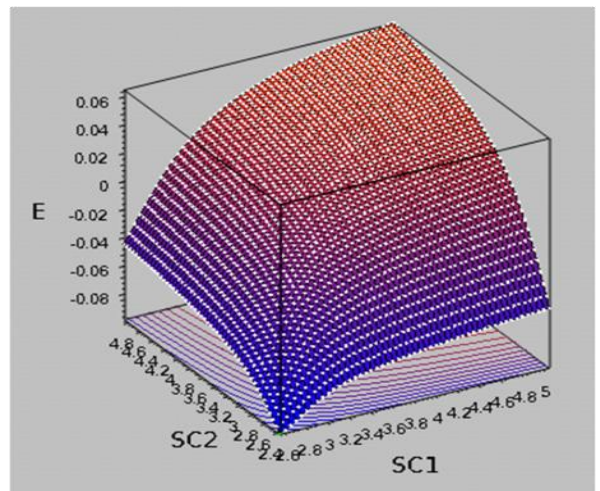

Fig. 4. The potential energy surface (PES) scan along $\mathrm{C}-\mathrm{Br}$ and $\mathrm{C}-\mathrm{Cl}$ distance.

\section{B. Understanding the Effectiveness of Sunscreen}

Computational chemistry can not only tackle the difficult concepts as demonstrated above, but also investigate relevant cases such as the effectiveness of sunscreen.

These types of exercises are similar to the context-led approaches, which use real life scenarios to understand 
chemistry principles. For example, the purpose of sunscreen is to block out the harmful ultraviolet (UV) lights such as UVA (320-400 nm), UVB (290-320 nm) and UVC (100-290 $\mathrm{nm})$. The commonly available sunscreen chemicals utilize (1) physical blockers such as zinc oxide and titanium dioxide, which gives the white color, and the conjugated $\pi$-system molecules to absorb (aka block) UV lights. Because the atmospheric gases and ozone can absorb most of UVC lights, the main function of sunscreen is to absorb UVA and UVB lights. This study can make a role-play by asking students to design a new sunscreen mixture for a new line of sunscreen products.

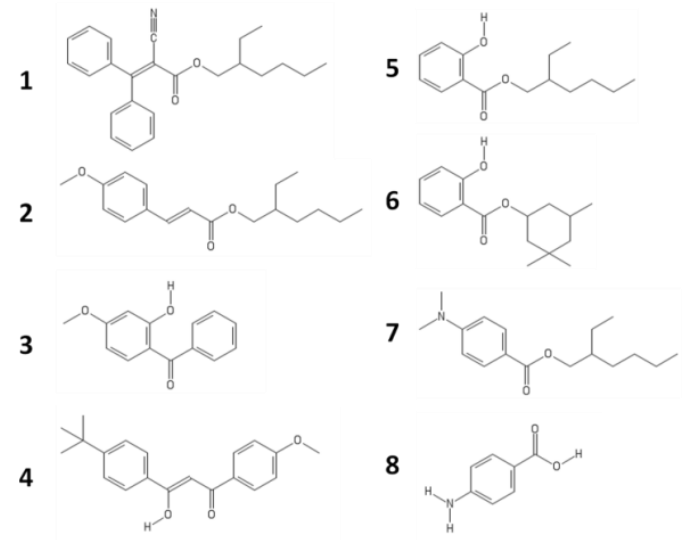

Fig. 5. Compounds with conjugated $\pi$-system investigated in suncreen project.

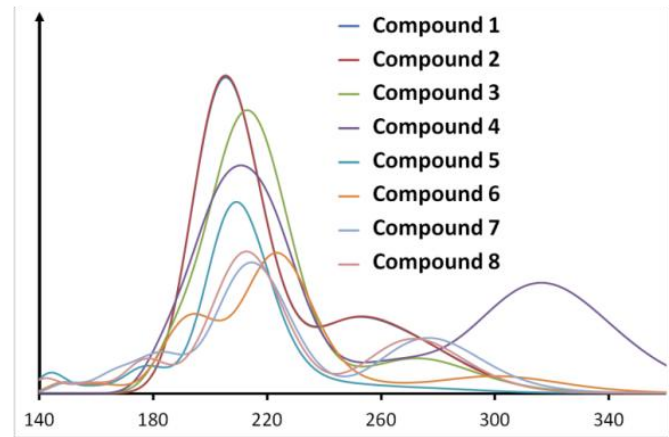

Fig. 6. The predicted UV-Vis spectra of above eight compounds using ZINDO methods.

The type of conjugated systems such as those chemical compounds in Fig. 5 can be used to model the UV-Vis spectra as those measured by UV spectrophotometer. Of course students can use any other compounds in any chemical catalog. The main method used in this modeling is a semi-empirical quantum chemistry named Zerner's Intermediate Neglect of Differential Overlap (ZINDO) [22]. ZINDO can produce the excited states and UV-Vis spectra of these compounds. The predicted UV-Vis of these eight compounds is shown in Fig. 6. By examining the main absorption peak at various wavelengths, students can then identify which one(s) are the best combinations for sunscreen.

\section{Other Modules}

There are many online resources such as a tutorial for the software available for computational chemistry and molecular modeling in chemistry instruction. Especially in organic and physical chemistry, there are many examples in the textbook can be modeled and compared. Table II lists the example list of modules developed.
TABLE II: THE EXAMPLE LIST OF MODULES DEVELOPED

\begin{tabular}{ll}
\hline \hline Title & Concepts explained \\
\hline Identify isomer equilibrium & $\begin{array}{l}\text { Chirality and R/S designation, } \\
\text { Equilibrium constant, }\end{array}$ \\
\hline $\begin{array}{l}\text { Comparison between Benzene } \\
\text { and 1,3,5-cyclohexatriene }\end{array}$ & $\begin{array}{l}\text { Enthalpy, resonance stabilization, } \\
\text { enthalpy of formation, } \\
\text { delocalization effect }\end{array}$ \\
\hline Vibrational analysis of & $\begin{array}{l}\text { Infrared spectra, electron donating } \\
\text { and electron withdrawing groups }\end{array}$ \\
\hline functional groups & $\begin{array}{l}\text { Resonance structure, delocalization } \\
\text { of } \pi \text {-bond, effective barrier }\end{array}$ \\
\hline Polarities of molecules & $\begin{array}{l}\text { Dipole moments, Lewis dot } \\
\text { structure, VSEPR model, } \\
\text { electronegativity }\end{array}$ \\
\hline IR spectra vs molecular & $\begin{array}{l}\text { Group theory, point group, } \\
\text { irreducible representation, infrared } \\
\text { and Raman spectra, frequencies }\end{array}$ \\
\hline Ligand field strength & $\begin{array}{l}\text { Molecular orbital theory, bonding } \\
\text { and anti-bonding orbitals, } \\
\text { symmetry }\end{array}$ \\
\hline \hline
\end{tabular}

\section{CONCLUSIONS}

Computational chemistry and molecular modeling tools are becoming available and accessible to students. The calculation ability also becomes more and more powerful due to advancements made in the hardware design and software development. In this study we demonstrated various approaches that can be utilized to exemplify the difficult concepts found within the chemistry education, affording the students the necessary hands-on experiences that are essential in allowing them to generate their own opinion and conclusions.

\section{REFERENCES}

[1] Y. Kyle, S. Bacon et al., "Teaching chemistry effectively with engineering majors: Teaching Beyond the textbook," in Proc. 21st ICCE on Chemical Education and Sustainability in the Global Age, Springer, 2011.

[2] Public Perceptions of Chemistry, Qualitative Research, Management Report (Royal Society of Chemistry, 1995).

[3] G. Hinckley, Who Needs Chemistry, Faculty Resource Network, A National Symposium-Engaging Students in the Community and the World at Howard University, Washington DC, Nov. 2010

[4] CONFCHEM. (Winter 2004). How and Why Should We Tech Chemistry for Non-Science Majors. [Online]. Available: http://www.ched-ccce.org/confchem/2004/a/

[5] R. J. Merrill and D. W. Ridgway. (1969). The CHEM Study Story: a Successful Curriculum Improvement Project. W. H. Freeman: San Francisco. [Online]. Available: http://www.archive.org/details/chemstudystory00merr.

[6] Y. Shwartz, R. Ben-Zvi, and A. Hofstein, "Chemical Literacy: What Does This Mean to Scientists and School Teachers?" J. Chem. Educ., vol. 83, pp. 1557-1561, 2006.

[7] J. E. Ridley and M. C. Zerner, "An Intermediate Neglect of Differential Overlap Technique for Spectroscopy: Pyrrole and the Azines," Theor. Chem. Acc., vol. 32, pp. 111-34, 1973.

[8] M. J. Frisch, G. W. Trucks, H. B. Schlegel et al., Gaussian 09, Revision D.01, Gaussian, Inc., Wallingford CT, 2009.

[9] V. N. Staroverov, G. E. Scuseria, J. M. Tao, and J. P. Perdew, "Comparative assessment of a new nonempirical density functional: Molecules and hydrogen-bonded complexes," J. Chem. Phys., vol. 119, pp. 12129-12137, 2003.

[10] R. Ditchfield, W. J. Hehre, and J. A. Pople, "Self-consistent molecular orbital methods 9 extendedgaussian-type basis for molecular-orbital studies of organic molecules," J. Chem. Phys., vol. 54, pp. 724, 1971. 
[11] C. O'Neal, M. Wright, C. Cook, T. Perorazio, and J. Purkiss, "The impact of teaching assistants on student retention in the sciences: Lessons for TA training," Journal of College Science Teaching, vol. 36 no. 5, pp. 24-29, 2007.

[12] D. K. Smith "From crazy chemistrs to engaged learners through education," Nature Chemistry, vol. 3, pp. 681-684, 2011.

[13] B. W. Lloyd, "A review of curricular changes in the general chemistry course during the twentieth century," Journal of Chemical Education, vol. 69 , no. 8, pp. $633-636,1992$.

[14] MIT's OpenCourseWare website. [Online]. Available: http://ocw.mit.edu/courses/chemistry.

[15] POGIL website. Process Oriented Guided Inquiry Learning. [Online]. Available: http://www.pogil.org.

[16] PLTL website. Peer-led Team Learning. [Online]. Available: http://www.pltl.org.

[17] International Journal of Science Education, vol. 28, no. 9, 2006.

[18] A. Çam and G. Ömer, "Effectiveness of case-based learning instruction on epistemological beliefs and attitudes toward chemistry," J. Sci. Educ. Technol., vol. 20, pp. 26-32, 2011.

[19] L. W. Anderson and D. R. Krathwohl, A Taxonomy for Learning, Teaching and Assessing: A Revision of Bloom's Taxonomy of Educational Objectives, New York: Addison-Wesley Longman, 2001.

[20] B. S. Bloom, M. D. Engelhart, E. J. Furst, W. H. Hill, and D. R. Krathwohk, "Taxonomy of educational objectives: The classification of educational goals," Handbook I: Cognitive Domain, New York: David McKay, 1956.

[21] L. D. Fink, Creating Significant learning experiences: An Integrated Approach to Designing College Courses, San Francisco: Jossey-Bass, 2003.

[22] C. Wong and J. Currie, Teaching with Cache, Pacific University, 2002.

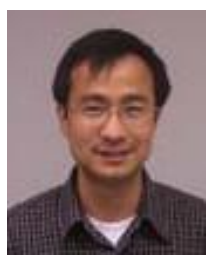

Hua-Jun Fan was born in Zhejiang Province, China in 1970. He graduated from University of Arizona as $\mathrm{PhD}$ in chemistry in 1999

$\mathrm{He}$ currently is an associate professor in the Department of Chemistry at Prairie View A\&M University, Texas, USA. During the summer of 2010 to 2012, he was awarded as a visiting professor for the Faculty and Student Team (FaST Program) and Visiting Faculty Program (VFP Program) at US Department of Energy Ames National Lab and Iowa State University, Ames, Iowa, USA. His research interests are computational modeling of reaction mechanism, electronic structure of nanocomposite materials and drug design.

Dr. Fan is a member of US American Chemical Society. Currently Dr. Fan holds grants from US Department of Energy, US Air Force Research laboratory, and US National Science Foundation. He has more than 20 journal publication and book chapters, and more than 40 scientific conference presentations and invited talks.

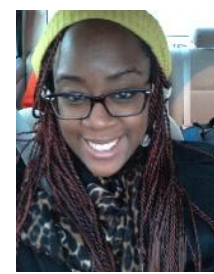

Nnenna Elechi was born in Oslo, Norway in 1992. She graduated with a bachelor's of science chemistry degree in May of 2013, and is currently pursuing her master's in chemistry. She has interned at Texas A\&M University computational lab multiple times and has also interned at the Los Alamos National Laboratory. Nnenna has also presented several posters at various ACS meetings.

Nnenna Elechi is a member of the American Chemical Society as well as the National Organization for Black Chemists and Chemical Engineers.

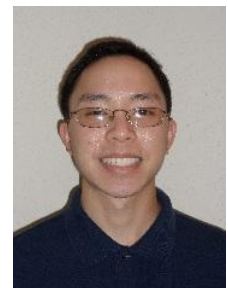

Daniel Tran was born in Houston, Texas in 1990. He is currently a student at Prairie View A\&M University. $\mathrm{He}$ is currently pursuing a degree in biomedical chemistry.

$\mathrm{He}$ is currently a research assistant at Prairie View A\&M University. He is interested in computational chemistry, as well as pharmaceuticals, nanotechnology, and materials design. Mr. Tran is a member of the American Chemical Society.

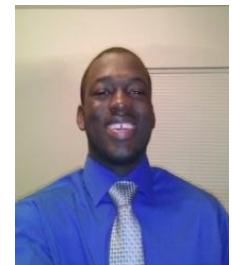

Joshua Heads was born in Houston, Texas in 1993 $\mathrm{He}$ is a student at Prairie View A\&M University pursing his bachelors of science degree in chemical engineering. He is a sophomore and is expected to graduate in May 2016

$\mathrm{He}$ currently holds a computational research position at Prairie View A\&M University. He is also team member of the American Institute of Chemical Engineers Chem-E car project.

Mr. Heads is a member of the American Institute of Chemical Engineers and the National Society of Black Engineers. 